\title{
Are Patients Undergoing an Elective Myocardial Revascularization Nowadays at Worse Pre-Surgery Quality of Life than Before?
}

\section{Ellen van der Straaten and Luc Noyez ${ }^{\star}$}

Department of Cardio-Thoracic Surgery, Nijmegen Medical Center, Radboud University, 615, PO Box 9101, 6500 HB Nijmegen, The Netherlands

*Corresponding author: Luc Noyez, Department of Cardio-Thoracic Surgery, Nijmegen Medical Center, Radboud University, 615, PO Box 9101, 6500 HB Nijmegen, The Netherlands, Tel: +31-24-3613711; Fax: +31-24-3540129; E-mail: Luc.Noyez@radboudumc.nl

Rec date: Jan 27, 2016; Acc date: Feb 19, 2016; Pub date: Feb 22, 2016

Copyright: (C) 2016 Straaten EVD, et al. This is an open-access article distributed under the terms of the Creative Commons Attribution License, which permits unrestricted use, distribution, and reproduction in any medium, provided the original author and source are credited.

\begin{abstract}
Background: The purpose of this study is to outline whether patients, undergoing elective myocardial revascularization nowadays have a better or worse preoperative Quality of Life $(\mathrm{QoL})$ than years ago.

Methods: The EuroQol instrument, EQ-5D and EQ-VAS is used for assessing QoL. Preoperative QoL data of 3175 patients undergoing elective isolated coronary bypass operations, January 2002-December 2013 were analyzed. The total group was divided into three time cohorts. Group A (879 patients) operated between January 2002 and December 2005, group B (944 patients) operated between January 2006 and December 2009, and group C (1352 patients) operated between January 2010 and December $2013(n=803)$.
\end{abstract}

Results: There is no statistical significant difference among the three groups for the registered EQ-5D index. The registered EQ-VAS index is significantly lower for group $A$ versus $B$ and $C(p=0.001)$. The domains of the $E Q-5 D$, 'mobility', 'usual activities' and 'pain/discomfort' show a statistically significant difference over time with an increased percentage of patients with no problems in these domains. However, in contrast with these domains, the domain anxiety/depression, shows, a statistical significant increase of the percentage patients with problems.

Conclusion: Patients nowadays are not at a worse QoL than years ago. Nevertheless, the percentage of patients with anxiety and problems of depression increased the last years.

Keywords: Cardiac surgery; Quality of life; Coronary artery; Bypass surgery

\section{Introduction}

Quality of life (QoL) has become an increasingly important aspect in medicine, social sciences and health services over the last years. Particularly in cardiac surgery, with an increasing number of elderly patients, an improved QoL is beside survival a major goal [1]. Several studies suggest the impact of patients preoperative QoL not only on postoperative Qol, but also on postoperative morbidity and survival $[2,3]$. Recently, several reports concerning oncological surgery suggested that QoL can provide an early indicator for patients at risk of complications $[4,5]$. Therefore, it is interesting to study the trends concerning preoperative QoL of patients undergoing cardiac surgery in a recent patient population, so that eventually problems can be identified and the support put in place for decision-making in financial and ethical aspects and even in further research concerning coronary artery surgery.

In this study, we present data of systematic preoperative QoLregistration in patients undergoing an isolated elective CABG during the last decade. The purpose of this study is to outline whether patients nowadays have a better or worse preoperative QoL than years ago.

\section{Patients and Methods}

\section{Quality of life registration}

To assess QoL, both components of the EuroQOL instrument (EQ-5D and EQ-VAS) were used [6]. This is a validated and standardized generic instrument to measure QoL. The EQ-5D consists of five domains of health (Mobility, Self-Care, Usual Activities, Pain/ Discomfort, and Anxiety/Depression), each of which is divided into three levels: no problems (i), some or moderate problems (ii) and extreme problems (iii). Based on the response to this classification, a single index value is estimated using a general population-based algorithm [7]. The EQ-5D index spans a scale from -0.54 to 1.0, with greater scores indicating better quality of life. For the EQ-VAS, patients estimate their own health on a visual analogue scale ranging from 0 to 100 , with 0 being the worst possible health state and 100 being the best. The EQ-5D index can be regarded as a societal-based composite global QoL measurement, whereas the EQ-VAS is a direct global QoL assessment from the patient's perspective.

All Patients undergoing cardiac surgery were asked to individually complete the preoperative QoL questionnaire on the day before surgery. Therefore, but also for ethical reasons, only patients undergoing elective surgery were included in our QoL studies. It concerns a written questionnaire that the patient receives at the moment of hospital admission for the operation. Patients are informed that there is no obligation to complete this questionnaire, that data will only be used for clinical research and that they will receive one, two 
and five years postoperative the same questionnaire by correspondence, again without any obligation to complete the questionnaire.

To get an idea about possible trends within the 5 different domains of the EQ-5D, we evaluated the percentages of patients in the three different levels of each domain.

\section{Patients}

From our Cardiac Surgery Database Radboud Hospital (CORRAD)a database that stores pre-, peri-, and post-operative data plus followup data, inclusive preoperative and follow-up QoL data, from all adult patients undergoing cardiac surgery at the Radboud University Medical Centre Nijmegen -we identified 5514 patients undergoing an isolated CABG between January 2002 and December 2013. After exclusion of non-elective patients and patients with a history of a recent infarction as defined in the EuroSCORE, (7) 4488 patients are left. Complete preoperative EQ-VAS and EQ-5D are available from 3175 patients $(70.7 \%)$, this group is our study group. The 12 studied years are arbitrary subdivided into three time cohorts of 4 years: group A (879 patients) operated between January 2002 and December 2005, group B (944 patients) operated between January 2006 and December 2009, and group C (1352 patients) operated between January 2010 and December 2013

\section{Risk stratification and data registration}

The additive EuroSCORE is used for all patients and since 2006, also the logistic EuroSCORE is used $[8,9]$. The registration of the data in the CORRAD database and the use of this information for research have been approved by the local ethical and research council of the Radboud University Nijmegen [10].

\section{Endpoints of the study}

This study has two major endpoints.

Are patients undergoing elective CABG nowadays at worse or at better preoperative QoL?

Is there a difference concerning the five domains of the EQ-5D over the years?

It must be clear that in this study we focus on these two endpoints and make no further analysis on relations between basic patient's characteristics, risk and morbidity and preoperative QoL.

\section{Statistical analysis}

The characteristics of patients in groups A, B and C are presented as percentages for dichotome variables and for numerical variables as mean \pm standard deviation (S.D.), range and in the tables also as median with Inter Quartile Range (IQR). Differences for numeric variables in the three groups were tested with the F-test (one way analysis of variance) followed by a post hoc Tuckey test and differences in percentage were tested with the chi-square test. Statistical significance was assumed at $\mathrm{P} \leq 0.05$.

\section{Results}

Table 1 presents age, gender and calculated operative EuroSCORE risk of studied patient population. There is no statistically significant difference for gender and additive EuroSCORE risk between the three groups. The logistic EuroSCORE risk, only available since January 2006, and therefore not calculated for group A, shows also no statistical significant difference between group B and C. For age there is a statistically significant difference between the three groups. However only the increase in age between group $A$ and $B(p=0.001)$ and between group $A$ and $C(p=0.001)$ is statistical significant.

\begin{tabular}{|c|c|c|c|c|}
\hline Variable & $\begin{array}{l}\text { Group A } \\
\mathrm{N}=879\end{array}$ & $\begin{array}{l}\text { Group B } \\
\mathrm{N}=944\end{array}$ & $\begin{array}{l}\text { Group C } \\
N=1352\end{array}$ & $\begin{array}{l}p- \\
\text { value }\end{array}$ \\
\hline \multicolumn{5}{|l|}{ Age* $^{*}$} \\
\hline Mean \pm SD & $64.3 \pm 9.6$ & $65.9 \pm 9.1$ & $66.2 \pm 9.6$ & \multirow[t]{3}{*}{0.001} \\
\hline (range) & $(18.3-84.8)$ & $(35.4-93.0)$ & $(22.9-89.9)$ & \\
\hline Median (IQR) & $65.0(57.5-71.7)$ & $66.1(59.9-72,4)$ & $66.6(60.1-73.4)$ & \\
\hline Female gender & $173(19.7)$ & $195(20.7)$ & $278(20.6)$ & 0.846 \\
\hline \multicolumn{5}{|c|}{ Add EuroscoRE } \\
\hline Mean \pm SD & $2.77 \pm 2.2$ & $2.81 \pm 2.1$ & $2.92 \pm 2.1$ & \multirow[t]{3}{*}{0.085} \\
\hline (range) & $(0-11)$ & $(0-11)$ & $(0-11)$ & \\
\hline Median (IQR) & $2.0(1-4)$ & $3.0(1-4)$ & $3.0(1 .-4)$ & \\
\hline \multicolumn{5}{|c|}{ Log EuroSCORE** } \\
\hline Mean \pm SD & & $2.8 \pm 2.6$ & $2.9 \pm 2.9$ & 0.526 \\
\hline (range) & & $(0.88-22.3)$ & $(0.88-51.1)$ & \\
\hline Median (IQR) & & $1.9(1.2-3.3)$ & $1.9(1.2-3.4)$ & \\
\hline
\end{tabular}

Table 1: Age, gender and calculated operative EuroSCORE risk of studied patient population. $\mathrm{SD}=$ standard deviation, $\mathrm{IQR}=$ interquartile range. ${ }^{*}$ Group $A$ versus $B=0.001$, group $A$ versus $C: p=0.001$, group $B$ versus $\mathrm{C}$ : not significant. ${ }^{*}$ Logistic EuroSCORE in group $\mathrm{A}$ not available.

It is important is to realize that the 1313 patients not included in the study group because of lack of complete QoL information are statistically significant older, 66.4 years versus 65.9 years $(p=0.012)$, at higher additive EuroSCORE risks 3.4 versus $2.8(\mathrm{p}=0.001)$ and logistic EuroSCORE risk 3.3 versus $2.8(\mathrm{p}=0.001)$. The percentage of patients not included, group A: $30 \%$, group B: $29 \%$, group C: $29 \%$ is not significant different between the three time cohorts $(p>0.05)$ and in each cohort age and risk is significant higher than the included patients.

\section{Are patients undergoing cardiac surgery nowadays at worse or at better QoL preoperative?}

Table 2 presents the results for the EQ-5D index score and the EQVAS Score. There is no statistical significant difference among the three groups for the registered EQ-5D index. The registered EQ-VAS index is significantly lower for group A versus B and C $(p=0.001)$.

\begin{tabular}{|l|l|l|l|l|}
\hline Variable & $\begin{array}{l}\text { Group A } \\
\text { N=879 }\end{array}$ & $\begin{array}{l}\text { Group B } \\
\text { N=944 }\end{array}$ & $\begin{array}{l}\text { Group C } \\
\text { N=1352 }\end{array}$ & $\begin{array}{l}\text { p- } \\
\text { value }\end{array}$ \\
\hline EQ-5D & \multicolumn{5}{|l}{} \\
\hline Mean \pm SD & $0.704 \pm 0.250$ & $0.687 \pm 0.273$ & $0.713 \pm 0.265$ & 0.079 \\
\hline
\end{tabular}


Page 3 of 4

\begin{tabular}{|c|c|c|c|c|}
\hline (range) & $(-0.128-1,00)$ & $(-0.272-1.00)$ & $(-0.304-1)$ & \\
\hline $\begin{array}{l}\text { Median } \\
\text { (IQR) }\end{array}$ & $\begin{array}{l}0.775 \\
(0.651-0.843)\end{array}$ & $\begin{array}{l}0.775 \\
(0651-0.843)\end{array}$ & $\begin{array}{l}0.805 \\
(0.683-0.843)\end{array}$ & \\
\hline \multicolumn{5}{|l|}{ EQ-VAS } \\
\hline Mean \pm SD & $59.5 \pm 22.0$ & $60.5 \pm 21.6$ & $61.4 \pm 20.9$ & \multirow[t]{3}{*}{0.005} \\
\hline (range) & $(0-100)$ & $(0-100)$ & $(0-100)$ & \\
\hline $\begin{array}{l}\text { Median } \\
\text { (IQR) }\end{array}$ & [60] (50-75) & [60.0], (50-77) & $65.0(50-80)$ & \\
\hline
\end{tabular}

Table 2: EQ-5D and EQ-VAS.

Table 3 shows the different response-rate to the five domains of the EQ-5D. For the domain 'selfcare', there is no statistical difference over the studied years. More than $90 \%$ of the patients assert to have no problems with selfcare, the last period this is even increased to $95 \%$. The domains 'mobility', 'usual activities' and 'pain/discomfort' show a statistically significant difference over time with an increased percentage of patients with no problems in these domains. The domain anxiety/depression shows also a statistical significant different response rate over the years, however in contrast with the other domains we have a statistical significant increase of the percentage patients with problems in this domain.

\begin{tabular}{|c|c|c|c|c|}
\hline EQ-5D Domain & $\begin{array}{l}\text { Group A } \\
\mathrm{N}=879\end{array}$ & $\begin{array}{l}\text { Group B } \\
N=944\end{array}$ & $\begin{array}{l}\text { Group C } \\
\mathrm{N}=1352\end{array}$ & $\begin{array}{l}p- \\
\text { value }\end{array}$ \\
\hline \multicolumn{5}{|l|}{ Mobility } \\
\hline no problems & $\begin{array}{l}492 \\
(56.0 \%)\end{array}$ & $\begin{array}{l}521 \\
(55.2 \%)\end{array}$ & $969(71.7 \%)$ & \multirow[t]{3}{*}{0.001} \\
\hline $\begin{array}{l}\text { some or moderate } \\
\text { problems }\end{array}$ & $\begin{array}{l}354 \\
(40.3 \%)\end{array}$ & $\begin{array}{l}379 \\
(40.1 \%)\end{array}$ & $347(26.7 \%)$ & \\
\hline extreme problems & $33(3.8 \%)$ & $44(4.7 \%)$ & $36(2.7 \%)$ & \\
\hline \multicolumn{5}{|l|}{ Selfcare } \\
\hline no problems & $\begin{array}{l}817 \\
(92.9 \%)\end{array}$ & $\begin{array}{l}877 \\
(92.9 \%)\end{array}$ & $\begin{array}{l}1287 \\
(95.2 \%)\end{array}$ & 0.110 \\
\hline $\begin{array}{l}\text { some or moderate } \\
\text { problems }\end{array}$ & $47(5.3 \%)$ & $54(5.7 \%)$ & $52(3.8 \%)$ & \\
\hline extreme problems & $15(1.7 \%)$ & $13(1.4 \%)$ & $13(1.0 \%)$ & \\
\hline \multicolumn{5}{|l|}{ Usual activities } \\
\hline no problems & $\begin{array}{l}547 \\
(62.2 \%)\end{array}$ & $\begin{array}{l}633 \\
(67.1 \%)\end{array}$ & $969(71.7 \%)$ & 0.001 \\
\hline $\begin{array}{l}\text { some or moderate } \\
\text { problems }\end{array}$ & $\begin{array}{l}287 \\
(32.7 \%)\end{array}$ & $\begin{array}{l}277 \\
(29.3 \%)\end{array}$ & $312(23.1 \%)$ & \\
\hline extreme problems & $45(5.1 \%)$ & $34(3.6 \%)$ & $71(5.3 \%)$ & \\
\hline \multicolumn{5}{|l|}{ Pain/ discomfort } \\
\hline no problems & $\begin{array}{l}226 \\
(25.7 \%)\end{array}$ & $\begin{array}{l}243 \\
(25.7 \%)\end{array}$ & $450(33.3 \%)$ & \multirow[t]{3}{*}{0.001} \\
\hline $\begin{array}{l}\text { some or moderate } \\
\text { problems }\end{array}$ & $\begin{array}{l}555 \\
(63.1 \%)\end{array}$ & $\begin{array}{l}573 \\
(60.7 \%)\end{array}$ & $766(56.7 \%)$ & \\
\hline extreme problems & $98(11.1 \%)$ & $\begin{array}{l}128 \\
(13.6 \%)\end{array}$ & $136(10.1 \%)$ & \\
\hline
\end{tabular}

\begin{tabular}{|c|c|c|c|c|}
\hline \multicolumn{5}{|l|}{ Anxiety/depression } \\
\hline no problems & $\begin{array}{l}530 \\
(60.3 \%)\end{array}$ & $\begin{array}{l}531 \\
(56.2 \%)\end{array}$ & 695 (51.4\%) & 0.001 \\
\hline $\begin{array}{l}\text { some or moderate } \\
\text { problems }\end{array}$ & $\begin{array}{l}316 \\
(35.7 \%)\end{array}$ & $\begin{array}{l}359 \\
(38.0 \%)\end{array}$ & $555(41.1 \%)$ & \\
\hline extreme problems & $33(3.8 \%)$ & $54(5.7 \%)$ & $102(7.5 \%)$ & \\
\hline
\end{tabular}

Table 3: Response to different domains of the EQ-5D.

\section{Discussion}

In this study, data concerning preoperative QoL registration of patients undergoing cardiac surgery over a period of 12 years are presented. At that point, this study is already unique. Most studies do even not provide any information about preoperative QoL, as we already focused on in a previous report and recently confirmed by Shan et al. $[1,11]$.

Over the studied period, we did not find a statistically significant difference in the registered EQ-5D index among the three time periods, suggesting that there is no change in the societal-based composite global QoL. However, if we take a look to the different domains of the EQ-5D, we have a statistically significant increase of the percentage of patients without problems for the domains mobility, usual activity, and pain/discomfort. In the domain 'anxiety/depression' in contrast, the percentage of patients without problems did significantly decrease. Despite the EQ-5D index scores show no change in QoL over the studied period, our data show a higher percentage of patients with complaints for the domain anxiety/ depression over the years. Of course several variables, as age, gender, education level, previous surgical experiences, and others can be responsible for the pre-operative anxiety/ depression [12] - but this is not the focus of the study.

The increased percentage of patients with anxiety/depression, is an interesting and important finding because Székely et al. and Tully et al. stated in their publications that psychosocial factors, particularly anxiety, is a predictor for morbidity and mortality post CABG $[2,13]$ and also recent publications concerning oncological surgery suggest a relation between QoL and morbidity and survival [4,5]. The other domains,-mobility, usual activity, and pain/discomfort -, show the same trend: lower percentages of patients with problems in group C. These domains, in particular 'mobility' and 'usual activity', are dependent of a lot of social provisions resulting in a better home care. The combination of an increased percentage with problems in the domain anxiety/depression with the decrease of these percentages in the other domains of the EQ-5D resulted in a 'stable' global EQ-5D registration over the studied years.

The EQ-VAS shows a statistically significant higher value for group C. This EQ-VAS represents the subjective assessment of patients' QoL and Whynes and the TOMBOLA Group descriped correspondence between the EQ-5D and the EQ-VAS, [14] ....) and the subjective 'good-feeling' of people is certainly influenced by variables as mobility, self-care, possibly to be able to perform usual activities.

Our study has of course several limitations. Firstly, it is a single center experience, based on patients undergoing an elective isolated myocardial revascularization. This is, of course, a low risk population. Secondly there is the problem with missing data, as we described 
Citation: Straaten EVD, Noyez L (2016) Are Patients Undergoing an Elective Myocardial Revascularization Nowadays at Worse Pre-Surgery Quality of Life than Before?. J Health Edu Res Dev 4: 158. doi:10.4172/2380-5439.1000158

Page 4 of 4

already [15]. However, our QoL registration over these years is practically unique.

At least, despites the EuroQoL is a validated and internationally accepted scoring system for registration of quality of life, it is not frequently used in cardiac surgery research.

We realize that this study is only a first step and that further studies, are needed to clarify the incidence of preoperative anxiety/depression and the relationship between it and preoperative risk factors and eventual postoperative morbidity.

In conclusion, this study suggests that patients nowadays are not at a worse QoL than years ago. Nevertheless, it is an important finding that patients seem to be more anxious or depressed over time, particularly because it is suggested that this domain is a possible predictor for increased morbidity and mortality in cardiac surgery.

\section{References}

1. Noyez L, de Jager MJ, Markou AL (2011) Quality of life after cardiac surgery: underresearched research. Interact Cardiovasc Thorac Surg 13: 511-514.

2. Noyez L, Markou AL, van Breugel FC (2006) Quality of life one year after myocardial revascularization. Is preoperative quality of life important. Interact Cardiovasc Thorac Surg 5: 115-120.

3. Székely A, Balog P, Benkö E, Breuer T, Székely J, et al. (2007) Anxiety predicts mortality and morbidity after coronary artery and valve surgery--a 4-year follow-up study. Psychosom Med 69: 625-631.

4. Doll KM, Snavely AC, Kalinowski A, Irwin DE, Bensen JT, et al. (2014) Preoperative quality of life and surgical outcomes in gynecologic oncology patients: a new predictor of operative risk. Gynecol Oncol 133: 546-551.
5. Bingener J, Sloan JA, Novotny PJ, Pockaj BA, Nelson H (2015) Perioperative Patient-Reported Outcomes Predict Serious Postoperative Complications: a Secondary Analysis of the COST Trial. J Gastrointest Surg 19: 65-71.

6. Brooks R (1996) EuroQol: the current state of play. Health Policy 37: 53-72.

7. Dolan P (1997) Modeling valuations for EuroQol health states. Med Care 35: 1095-1108.

8. Nashef SAM, Roques F, Michel P, Gauducheau E, Lemeshow S, et al. (1999) The EuroSCORE study group. European system for cardiac preoperative risk evaluation (EuroSCORE). Eur J Cardiothorac Surg 16: 9-13.

9. Roques F, Michel P, Goldstone AR, Nashef SA (2003) The logistic EuroSCORE. Eur Heart J 24: 881-882.

10. Wouters CW, Noyez L (2004) Is no news good news? Organized followup, an absolute necessity for the evaluation of myocardial revascularization. Eur J Cardiothorac Surg 26: 667-670.

11. Shan L, Saxena A, McMahon R, Wilson A, Newcomb A (2013) A systematic review on the quality of life benefits after aortic valve replacement in the elderly. J Thorac Cardiovasc Surg 145: 1173-1189.

12. Ebirim L, Tobin M (2010) Factors responsible for pre-operative anxiety in elective surgical patients at a university teaching hospital: a pilot study. The International Journal of anesthesiology 29: 1-10.

13. Tully PJ, Baker RA (2012) Depression, anxiety, and cardiac morbidity outcomes after coronary artery bypass surgery: a contemporary and practical review. J Geriatric Cardiology 9: 197-208.

14. Whynes DK, Tombola Group (2008) Correspondence between EQ-5D health state classifications and EQ VAS scores. Health Qual Life Outcomes 6: 94.

15. Noyez L (2014) Is quality of life post cardiac surgery overestimated. Health Qual Life Outcomes 12: 62. 